\title{
Humanitarian Surgical Missions in Times of COVID-19: Recommendations to Safely Return to a Sub-Saharan Africa Low- Resource Setting
}

\author{
Víctor Lopez-Lopez ${ }^{1}$ (1) Ana Morales ${ }^{2} \cdot$ Elisa García-Vazquez $^{3} \cdot$ Miguel González $^{4} \cdot$ Quiteria Hernandez $^{1}$. \\ Alberto Baroja-Mazo ${ }^{5}$ - Dolores Palazon ${ }^{1} \cdot$ Jose A. Tortosa $^{6} \cdot$ Maria A. Rodriguez $^{7} \cdot$ Nuria M. Torregrosa $^{8}$. \\ Winnie Kanyi ${ }^{9} \cdot$ J. K. Ndungu ${ }^{10} \cdot$ José Gil Martinez $^{1} \cdot$ José M. Rodriguez $^{1}$
}

Accepted: 31 January 2021/Published online: 20 February 2021

(C) Société Internationale de Chirurgie 2021

\begin{abstract}
Background Since the declaration of the pandemic, humanitarian medicine has been discontinued. Until now, there have been no general recommendations on how humanitarian surgical missions should be organized.

Methods Based on our experience in the field of humanitarian surgical missions to Sub-Saharan Africa, a panel of recommendations in times of COVID-19 was developed. The fields under study were as follows: (1) Planning of a multidisciplinary project; (2) Organization of the infrastructure; (3) Screening, management and treatment of SARSCOV-2; (4) Diagnostic tests for SARS-COV-2; (5) Surgical priorization and (6) Context of patients during healthcare assistance. We applied a risk bias measurement to obtain a consensus among humanitarian health-care providers with experience in this field.

Results A total of $94.36 \%$ of agreement were reached for the approval of the recommendations. Emergency surgery must be a priority, and elective surgery adapted. For emergency surgery, we established a priority level $1 \mathrm{a}(<24 \mathrm{~h})$ and $1 \mathrm{~b}(<72 \mathrm{~h})$. For an elective procedure, according our American College of Surgeon adaptation score, process with more than 60 points should be reconsidered. Due to the low life expectancy in many African countries, we consider 45-50 years as age of risk. In case of SARS-COV-2 active infection or high clinical suspicion, the screening, management and treatment should be following the international guidelines adapted to duration of the stay, available infrastructure, size of the cooperation team and medical resources.

Conclusions Humanitarian surgical mission in times of COVID-19 is a challenge that must extrapolate the established recommendations to the local cooperation environment.
\end{abstract}

Supplementary Information The online version contains supplementary material available at (https://doi.org/10.1007/s00268021-06001-x).

Víctor Lopez-Lopez

victorrelopez@gmail.com

1 Department of Surgery, Virgen de la Arrixaca Clinic and University Hospital, IMIB-Arrixaca, El Palmar, Murcia, Spain

2 Department of Neurology, Virgen de la Arrixaca University Hospital, IMIB-Arrixaca, Murcia, Spain

3 Department of Internal Medicine, Virgen de la Arrixaca University Hospital, IMIB-Arrixaca, Murcia, Spain
4 Department of Surgery, Reina Sofía University Hospital, Murcia, Spain

5 Digestive and Endocrine Surgery and Transplantation of Abdominal Organs, Biomedical Research Institute of Murcia, IMIB-Arrixaca, Murcia, Spain

6 Department of Anesthesiology, Molina Hospital, Murcia, Spain

7 Department of Maxilofacial Surgery, Virgen de la Arrixaca University Hospital, IMIB-Arrixaca, Murcia, Spain 


\section{Introduction}

Since COVID-19 first appeared, it has spread rapidly across the globe causing a change in the operation of health-care services and to the establishment of strict, specific measures to control the pandemic [1]. The collateral damage caused by this totally necessary measure is the drastic reduction in humanitarian surgical missions in subSaharan Africa (SSA). Humanitarian medicine has been fundamental in maintaining basic levels of health in some of these countries [2].

According to the WHO the main causes of mortality in SSA are infections, infestations and transmissible diseases [3]. However, many of the deaths that occur in rural African communities are due to the lack of proper surgical care, meaning that there is an urgent need for collaboration in both surgical care and infrastructure/ surgical equipment [4-6].

Besides the current pandemic-related shortage of international health volunteers to support surgical care in these countries, there appears to be uncertainty as to how the deescalation of humanitarian health-care projects should be organized. The lack of adequate epidemiological control, the shortage of health education, the complex access to future vaccination programmes and the major difficulty in controlling a pandemic suggest that these countries will take longer than more developed nations to bring the pandemic under control [7-12]. Moreover, the limited access to a diagnostic test means that on many occasions patients must be treated with the same measures of protection used when treating an infected patient [13-15].

Most scientific societies have proposed guidelines for managing their patients in the COVID-19 era, but the state of sanitary equipment, socioeconomic conditions, and hygiene and cultural factors in SSA mean that such guidelines may be irrelevant in our own environment [16]. Different authors stressed their concern about how COVID-19 might affect access to safe surgery, especially in low-income countries [17-19].

The lack of consensus on the management of surgical patients in humanitarian medicine reveals the need to establish a plan of action. Based on our own experience of health-care assistance in the field of humanitarian medicine, and taking into consideration the general guidelines on the management of patients and medical staff in the COVID-19 era, the aim of this study was to generated

8 Department of Surgery, Santa Lucía University Hospital, Cartagena, Murcia, España

9 Health Muranga County, Maragua, Kenia

10 Department of Surgery Maragua Hospital, Maragua, Kenia recommendations and suggestions for humanitarian surgical missions so that they can be useful to all those who carry out humanitarian medicine.

\section{Methods}

Since 2000, our non-governmental organization "Cirugía Solidaria" has conducted 21 health-care assistance missions in SSA, during which a total of 14,394 patients have been seen (including more than 4,000 children). Of these patients, 4203 have received surgery for a range of pathologies, with special emphasis on the prioritization of processes according to their effectiveness. Given the duration of these activities and their excellent results, the health-care model of cooperation in SSA appeared to has been consolidated [20-23]; however, the reality of the COVID-19 pandemic means that this model now needs rethinking, as described below.

A working group was developed with an interest in humanitarian medicine, and the current situation caused by COVID-19 in low- and middle-income countries (Supplementary information). The fields under study were as follows: [1] Planning and development of a project involving multidisciplinary humanitarian health-care team; (2) Organization of the health-care infrastructure (consulting rooms, operating rooms and hospitalization areas); (3) Screening, management and treatment of active SARSCOV-2 infection; (4) Diagnostic tests for acute SARSCOV-2 infection; (5) Prioritization in the scheduling of patients for surgery and (6) Context of patients seen during a humanitarian health-care assistance. For each of the six fields of interest, two experts in humanitarian health-care assistance were assigned to establish the recommendations. Each of the experts conducted a literature research through MEDLINE/PubMed, Scopus, Embase, CINAHL or Web of Science to find relevant publications related to their points of interest. Keywords used in the search included a terms combination of "COVID-19," "SARS-CoV-2," "humanitarian surgery," "humanitarian medicine," "low- and middle-income countries," "testing," "vaccines," "drug treatment," "organization and administration" and "prevention and control." Furthermore, a manual search of references from relevant articles was performed.

After searching, discussions occurred both within the subgroup and with members of other subgroups. Later, a clearly defined set of suggestions was formulated about the organization of a humanitarian surgical mission in COVID19 times. Subsequently, the study coordinators contacted with a selection of international health volunteers with 
experience in the field of humanitarian medicine to perform a validation to the consensual recommendations. The evaluation committee was composed by surgeons, nursing staff, anesthetists, neurologists, nephrologists, internists, specialists in infectious diseases and emergencies, traumatologists, pediatricians and otolaryngologist. We apply a risk bias measurement to obtain a consensus among cooperators. In this way, we developed a checklist with 13 items for a critical evaluation of the quality of the recommendations. This checklist was inspired by the Downs and Black checklist [24], an instrument designed for evaluating different study designs (Supplementary information Table S1). A total of $94.36 \%$ of agreement were reached by all respondents for the approval of the recommendations and suggestions (Supplementary information Figure S1).

\section{Planning and development of a project involving multidisciplinary cooperation humanitarian health- care assistance}

Once a cooperation team has been formed, a pre-campaign commission must be set up to evaluate the epidemiological situation of the destination zone. The commission should be made up of members of the team, their local counterparts, government health authorities and corresponding health-care institutions. All team members must have a COVID PCR test done $48 \mathrm{~h}$ before departure. Any individual with symptoms indicating possible infection will be excluded from the expedition. The team must include two or more internists with specialist training in COVID-19. Most of the surgical and medical equipment should be sent on ahead and the rest, for example medication and COVID19 equipment, should be carried by the aid workers. In this way, we will be able to ensure that essential material is not in danger of contagion and will be readily available on arrival.

\section{Organization of the health-care infrastructure: consulting rooms, operating rooms and hospitalization areas}

This initial contact will identify cases of COVID-19 in the area and the possibility of conducting diagnostic tests. The crowding of patients waiting to be evaluated is common, and the safety distance must be organized ensuring the safety distance (Supplementary information Figure S2). Reducing the number of face-to-face consultations by encouraging remote consultations is difficult in SSA due to the absence of devices for telemedicine [25]. Even so, it should be attempted where necessary. Patients must be unaccompanied except in the case of minors or people requiring help for mobility. All patients must undergo screening for COVID-19 under the direction of the internists. They will then be referred for primary health-care screening to differentiate between possible medical and surgical pathologies.

In ideal conditions, there will be at least two independent blocks, so that one of them will always be available for scheduled or emergency management of a COVID-19 patient. The reprocessing of surgical equipment should be done following protocols for cleaning, disinfection and sterilization with moist heat (autoclave $134{ }^{\circ} \mathrm{C}$ ). During hospitalization, there must be a physical space set aside exclusively for patients with COVID-19 or suspected COVID-19. Priority should be given to early discharge, with a contact number provided for any complications.

The aim is to protect both patients and workers from the risks of SARS-CoV-2 infection and ensure health care $[26,27]$. It will be important for everybody on the expedition to avoid quarantine, which means establishing work groups that are balanced with regard to the workers' skills and functional units to which they belong (Table 1).

\section{Screening, management and treatment of active SARS-COV-2 infection}

As mentioned above, for the duration of the SARS-COV-2 pandemic, continual screening for the disease must be done in patients seeking medical or surgical evaluation as well as before and after treatment [28-31]. It will therefore be necessary to check for symptoms of COVID-19 and suspected infection during several key stages.

\section{Initial medical evaluation}

It will be crucial to conduct a clinical interrogation on the presence of respiratory symptoms and epidemiological contacts, as well as a physical exploration, auscultation of the lungs and pulse oximetry. The patient's epidemiological situation should also be determined, differentiating whether they are isolating for COVID-19 or positive for COVID-19, or have been in contact with a person who has tested positive for COVID-19 during the previous fortnight, or are health or special workers with a respiratory infection.

The data will be used to classify patients as having a high or low suspicion for COVID-19 infection. If feasible, a test to diagnose acute infection will be requested. The test can be done if circumstances permit (e.g., if it is available locally or provided by the aid workers). This will classify patients as COVID-19-positive, highly suspicious for COVID-19 (if the test is negative but clinical suspicion is very high) and COVID-negative. Patients who are COVIDpositive or highly suspicious for COVID-19 will be 
Table 1 Recommendations for health-care workers, non-health workers and family member in contact with persons having confirmed or suspected COVID-19.

Recommendations for the protection of humanitarian health-care providers

At least two "surgery units" consisting of a preoperative area, operating room and postoperative recovery area (ensuring a COVID-1 ${ }^{\mathrm{D}}$ zone).

Always maintain proper protective measures with a COVID-positive or suspected COVID-positive patient

Divide aid workers into closed stable work groups.

Try to minimize contact between workers without face covering during their rest breaks.

Try to ensure the dining room is spacious and allows a distance of $1.5 \mathrm{~m}$ between tables during mealtimes and is well aired. It should preferably be outdoors.

Continuous training of professionals about the use of PPE and the use of chemoprophylaxis and immunoprophylaxis as soon as available.

Recommendations regarding information to patients and family members

Detailed information about the risks and benefits of undergoing surgery in the transitory situation of the COVID-19 pandemic, and the risks if surgery is deferred.

Education campaigns for patients and family members in measures to prevent SARS-CoV-2 infection.

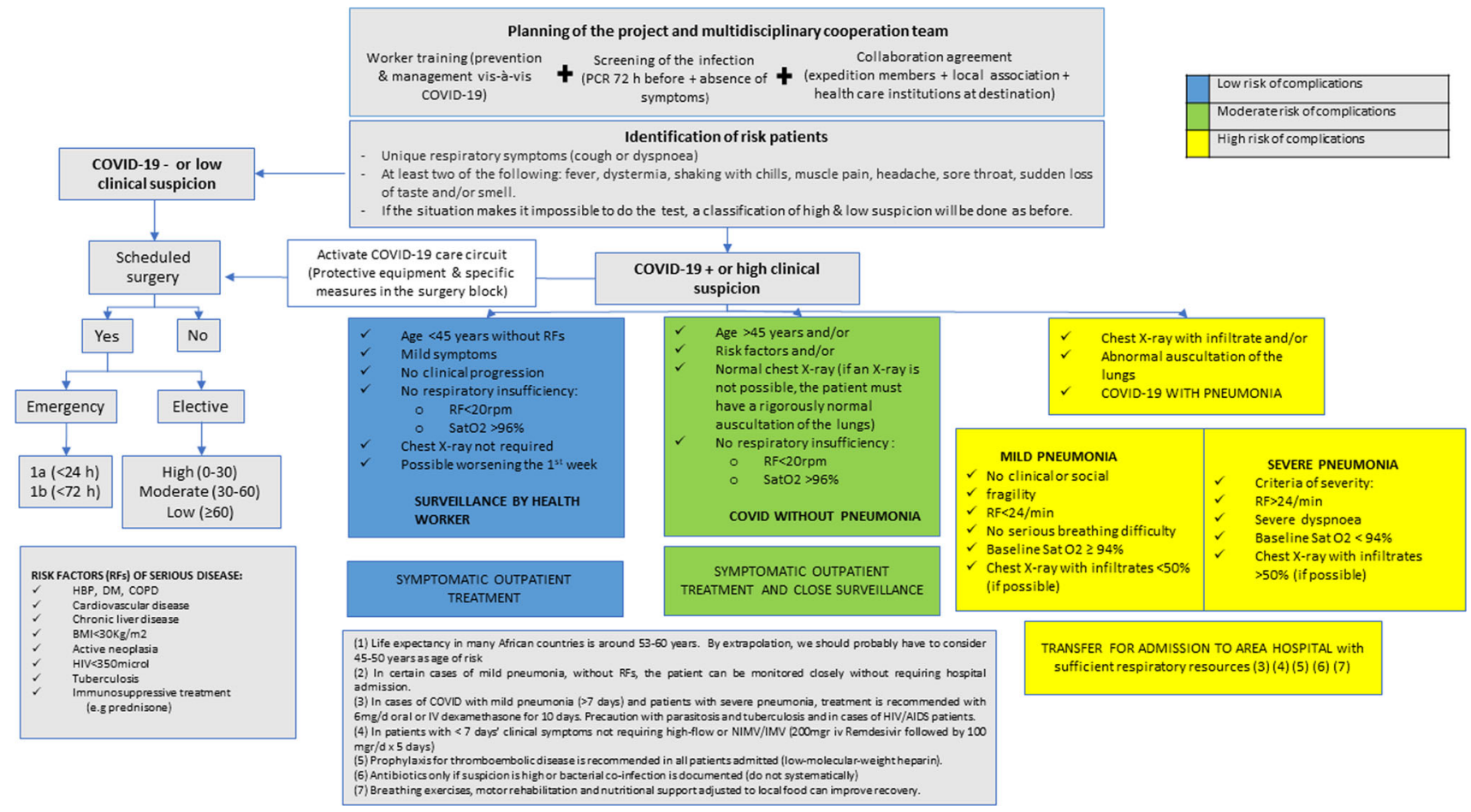

Fig. 1 Algorithm for planning a surgical health-care cooperation in times of COVID-19 in relation to the identification of patients at risk, surgical planification and management based on the symptoms associated with SARS-COV-2 infection. PCR: polymerase chain

stratified according to the clinical situation indicated in the following algorithm (Fig. 1).

\section{Perioperative evaluation}

If a patient requires surgical care, they will be sent to the corresponding consulting room, where the indication and priority for surgery will be established. During the surgery, reaction, RFs: risk factors, RF: respiratory frequency, HBP: high blood pressure; DM: diabetes mellitus; COPD: chronic obstructive pulmonary disease; BMI: body mass index; HIV: human immunodeficiency viruses

all the staff will follow the anaesthesiologist guidelines reported in the context of COVID-19 pandemic [32]. After the operation if any suspicious symptoms or signs are detected, the procedure will be as above and if possible will include a test and then clinical assessment and intervention according to the algorithm. 
Table 2 Recommendations for prioritization

Priority la-Emergency procedures to be performed ill $<24 \mathrm{~h}$

Emergency laparotomy

Postoperative complications

Appendectomy

Fractures, hemorrhages, vascular injuries and traumas

Drainage of localized sepsis-necrosis

Perforated esophagus/stomach

Acute airway obstruction

Major bums

Necrotizing fasciitis

Polytrauma due to road accident*

Stings, bites and wounds caused by machete, knife or firearm*

Testicular torsion*

Ectopic pregnancy complications

Emergencies related to pregnancy and childbirth (instrumental delivery, perineal repair, manual removal of placenta, cervical cerclage, hysterectomy, early pregnancy and abortion care)

Priority lb Procedures to be performed in- $==72 \mathrm{~h}$

Bowel obstruction, colectomy for acute severe ulcerative colitis, abscess ${ }^{1 /}$ other infection, urgent nutrition compromise, failed conservative management of localized intra-peritoneal infection, sphincter repair following rape*, incarcerated hernia*, goitres with respiratory compromise, acute abdomen in the context of typhoid disease*

Adaptation of the usual standards of treatment for an oncological surgical pathology based on available resources and reasons of expediency. Although chemotherapy or radiation therapy is not possible in this context, evaluate whether surgery might be curative or useful in preventing tumor-related complications

Prioritization of complex pathologies subsidiary to complications during the first few days

Potentially deferrable benign procedures in winch the only possibility of treatment is a cooperation surgical mission. Schedule during the campaign $\mathrm{m}$ response to resources

Potentially deferrable benign procedures in winch the only possibility of treatment is a cooperation surgical mission. Schedule during the campaign $\mathrm{m}$ response to resources

*Emergencies adapted to the context of international cooperation

\section{Information given to the patient and family members}

The patient will be given information on the safety measures to be taken, with special attention to frequent handwashing, social distancing and the use of hospital areas with more space and good ventilation. Aid workers should organize training activities regarding these measures in their country of origin (Table 1).

\section{Diagnostic tests for acute SARS-COV-2 infection}

According to currently available data, there are mainly two techniques for establishing a diagnosis of acute SARSCOV-2 infection [33]. The microbiological diagnosis of COVID-19 is based mainly on SARS-CoV-2 viral RNA detection using RT-PCR (Reverse transcription polymerase chain reaction) in a nasopharyngeal or oropharyngeal exudate. A more rapid alternative is antigen detection in nasopharyngeal exudate. The main advantage of this technique is that it provides a quick diagnosis $(15-20 \mathrm{~min})$ and is a simple, low-cost procedure that can be performed in the health-care center. This and similar tests on the market may be a good tool in the diagnostic strategy for COVID-19 in Africa [13, 14].

\section{Prioritization in the scheduling of patients for surgery}

The proper selection of patients for surgery is possibly the most important aspect of this approach [34, 35]. Patient screening over the first few days will be fundamental, and patients must be prioritized in anticipation of possible eventualities such as an outbreak or the need to slacken or suspend the health-care assistance. Prioritization must take into consideration the severity of the pathology and the risk of complications (depending on the type of surgery or patient). Emergency surgery must always be a priority, and elective surgery adapted to the characteristics of the project (duration of the stay, available infrastructure, size of the team and availability of medical resources). 
Table 3 ACS scale of surgical prioritization during the coronavirus pandemic in elective surgery adjusted to the population in which international collaborations are usually conducted

\begin{tabular}{|c|c|c|c|c|c|}
\hline & 1 & 2 & 3 & 4 & $F$ \\
\hline $\begin{array}{l}\text { Effectiveness of } \\
\text { conservative } \\
\text { treatment }\end{array}$ & $\begin{array}{l}\text { Non-existent/ } \\
\text { unavailable }\end{array}$ & $\begin{array}{l}\text { Effectiveness } \\
=40 \% \text { of that } \\
\text { provided by } \\
\text { surgery }\end{array}$ & $\begin{array}{l}\text { Effectiveness } \\
40-60 \% \text { of that } \\
\text { provided by } \\
\text { furgery }\end{array}$ & $\begin{array}{l}\text { Effectiveness } \\
60-95 \% \text { of that } \\
\text { provided by } \\
\text { surgery }\end{array}$ & $\begin{array}{l}\text { Effectiveness } \\
\text { totally equivalent } \\
\text { to surgery }\end{array}$ \\
\hline $\begin{array}{l}\text { Impact of a } 6 \\
\text { month deferral } \\
\text { on the disease }\end{array}$ & $\begin{array}{l}\text { Very serious } \\
\text { worsening }\end{array}$ & $\begin{array}{l}\text { Significant } \\
\text { worsening }\end{array}$ & $\begin{array}{l}\text { Moderate } \\
\text { worsening }\end{array}$ & Mild worsening & No worsening \\
\hline $\begin{array}{l}\text { Impact of a l } \\
\text { year deferral on } \\
\text { the disease }\end{array}$ & $\begin{array}{l}\text { Very serious } \\
\text { worsening }\end{array}$ & $\begin{array}{l}\text { Significant } \\
\text { worsening }\end{array}$ & $\begin{array}{l}\text { Moderate } \\
\text { worsening }\end{array}$ & Mild worsening & No worsening \\
\hline $\begin{array}{l}\text { Impact on social } \\
\text { \& work life }\end{array}$ & Yes & & & No & \\
\hline $\begin{array}{l}\text { Operating time } \\
\text { (min) }\end{array}$ & 30 & $30-60$ & $60-120$ & $120-180$ & $=180$ \\
\hline $\begin{array}{l}\text { Mean length of } \\
\text { tay }\end{array}$ & $\begin{array}{l}\text { Minor } \\
\text { surgery/Major } \\
\text { outpatient surgery }\end{array}$ & $=24 \mathrm{~h}$ & $24-48 \mathrm{~h}$ & 3 days & 4 days \\
\hline $\begin{array}{l}\text { Probability of } \\
\text { need for ICU }\end{array}$ & Improbable & $5 \%$ & $5-10 \%$ & $10-25 \%$ & $=25 \%$ \\
\hline Blood loss & $100 \mathrm{cc}$ & $100-250 \mathrm{cc}$ & $250-500 \propto c$ & $500-750 \mathrm{cc}$ & $=750 \mathrm{cc}$ \\
\hline $\begin{array}{l}\text { Surgical team } \\
\text { members }\end{array}$ & 1 & 2 & 3 & 4 & $=4$ \\
\hline Site & $\begin{array}{l}\text { None of the } \\
\text { following }\end{array}$ & $\begin{array}{l}\text { Upper \& lower } \\
\text { abdomen via } \\
\text { laparoscopy }\end{array}$ & $\begin{array}{l}\text { Lower abdomen } \\
\text { via open } \\
\text { approach }\end{array}$ & $\begin{array}{l}\text { Upper abdomen } \\
\text { via open } \\
\text { approach, } \\
\text { thyroid surgery }\end{array}$ & $\begin{array}{l}\text { Head \& neck, } \\
\text { chest, complex } \\
\text { esophagogastric }\end{array}$ \\
\hline Age: & 20 years & $20-40$ years & $40-50$ years & $50-65$ years & $=65$ years \\
\hline $\begin{array}{l}\text { Chronic lung } \\
\text { disease (COPD, } \\
\text { asthma, cystic } \\
\text { fibrosis) }\end{array}$ & No & & & $\begin{array}{l}\text { On-demand } \\
\text { treatment }\end{array}$ & Usual treatment \\
\hline OSAS & No & & & No treatment & N/A* \\
\hline $\begin{array}{l}\text { Cardiovascular } \\
\text { disease }\end{array}$ & No & & Yes & N/A* & $\mathrm{N} / \mathrm{A}^{*}$ \\
\hline BMI & $25 \mathrm{Kg} / \mathrm{m}^{2}$ & & & $25-30 \mathrm{Kg} / \mathrm{m} 2$ & $30 \mathrm{Kg} / \mathrm{m} 2$ \\
\hline $\begin{array}{l}\text { Type } 2 \text { diabetes } \\
\text { mellitus }\end{array}$ & No & & $\longdiv { Y e s }$ & N/A* & $\mathrm{N} / \mathrm{A}^{*}$ \\
\hline Flu syndrome & No & & & & Yes \\
\hline $\begin{array}{l}\text { Contact with } \\
\text { CovID-19 in } \\
\text { past fortnight }\end{array}$ & $\sqrt{\text { No }}$ & & Unsure & & Yes \\
\hline
\end{tabular}

Min: minutes; ICU: intensive care unit; COPD: chronic obstructive pulmonary disease; OSAS: Obstructive sleep apnea syndrome; BMI: body mass index. *Modifications made to original scale for the context of humanitarian medicine.

\begin{tabular}{|l|l|}
\hline & High prionity \\
\hline & Medium prionity \\
\hline & Low prionity \\
\hline & Low risk of complications \\
\hline & Moderate risk of complications \\
\hline & High risk of complications \\
\hline & Not applicable \\
\hline
\end{tabular}


To establish recommendations for prioritization we used the Clinical Guide to Surgical Prioritization during theCoronavirus Pandemic published by the Federation of Surgical Speciality Associations (FSSA) and the 9American College of Surgeons (ACS) and adapted it to the context of humanitarian medicine $(36,37)$. Foremergency surgery we established a priority level 1a (procedures to be performed in $<24$ hours) and $1 b$ (procedures to be performed in $<72$ hours), which we modified from the FSSA guide to include the mostcommon procedures we are likely to encounter in the context of humanitarian surgical missions (Table 2). Whereas some procedures that cannot be resolved via endoscopy or radiology would be automatically proposedfor surgical management.

To determine the priority of elective procedures we adapted the ACS scale to focus on the factors dependent on the base process, procedures, stage of the patient and/or presence of COVID-19 disease. We made a series of modifications to the scale to adjust it to the context of our activity. First of all, we modified the item "impact of deferral" by extending it to 6 months or 1 year, because the humanitarian health-care assistance take place at most twice per year and occasionally not even in the same place. Secondly, certain fields related to obstructive sleep apnoea syndrome and treatment of cardiovascular disease or diabetes were modified because there is no access to the necessary medications. Thirdly, we propose replacing the item "immunosuppression" with "impact of the pathology on work or social life." In this context, some people are disabled by pathologies such as hernias or giant hydroceles (Figure S2), which prevent them from doing any work. Another example is large goitres (Figure S2), which lead to young women not being able to marry and have children due to the social rejection they cause. Lastly, we colorcoded the scale according to priority and risk of complications to facilitate decision-making. The ACS scale proposes a cutoff point of 55-57 points for reconsidering how appropriate a procedure is. In our own context, it is probably the cases with an accumulated score of more than 60 points where the appropriateness of the elective procedure should be reconsidered, although the procedure should not necessarily be canceled. A customized evaluation will be carried out for each patient and the lower the score the more advisable the need for surgery. The scores for each process are 0-20 (high priority), 20-40 (medium priority) and 60 (low priority) (Table 3 ).

\section{Context of patients seen during a cooperation humanitarian health-care assistance}

The panorama of certain surgical pathologies in humanitarian health-care assistance needs to be reconsidered [35]. The context of these low- and medium-developed countries and the circumstances of a pandemic change the scenario significantly. In fact, many of the processes to be treated are benign, which means they have a temporary nature and can be deferred easily. But, we must not forget that those processes labeled as benign and can have an impact on health and social life in these environments.

It is important to remember that hernia surgery in most cases is a procedure that can be deferred [38, 39]. According to the indications of the European Hernia Society, recommendations will vary between countries with different levels of outbreak, resource utilization for COVID patients, local testing capacities and availability of PPE [40]. The problem is that more than $60 \%$ of the population of SSA is made up of farmers, and agricultural activities account for about $23 \%$. Physical work is therefore key to their professional and economic development, such that hernia repair is vitally important. Another example is thyroid pathology. Patients with stage III-IV goitres have a limited quality of life and cannot work, which implies a major financial loss for the family. All this gives these pathologies a different connotation to that in developed countries, as they have a greater effect on the local economy. Shaha et al. reported some principles regarding thyroid surgery during the COVID-19 pandemic, specifying without any clear guidelines that management depended primarily on the characteristics of the lesion (giving priority to tumor pathology) and on the pandemic-related pressure on hospitals [41]. Under the label "benign," we also find multiple pathologies that can be treated with outpatient procedures and which carry a low risk of contagion because of the reduced production of aerosols [42, 43]. However, despite causing a great deal of social harm they may be postponed because they are benign, and priority should be given to cases of acute infection, potential malignancy, uncontrollable pain, or a condition where the prognosis would become significantly worse.

\section{Conclusions}

A great deal of information has been published on how patients should be managed in the health-care settings of the more developed countries, but up until now there have been no guidelines on how humanitarian health-care assistance could be resumed. COVID-19 is far from disappearing completely, and it is crucial we do not forget the less developed countries, where the consequences of the pandemic may be even more devastating. The development of the vaccine will also mean a change in the organization of this humanitarian health-care assistance. The problem is that we still do not know when it will be available and much less how access to it will be in the lower- and middle-income countries. Although the development of these 
surgical missions depends on a number of factors, there must be some general, basic recommendations, in addition to specific recommendations on the screening and management of COVID-19, adapted to the special characteristics of the low-resource areas where this cooperation will take place. We are aware that the organization of these humanitarian health-care activities is complicated, which is why further studies are necessary so that cooperation can be resumed as soon as possible. The recommendations were established based on the experience in humanitarian medicine of the working group and the most outstanding findings in the literature related with COVID-19. To give more robustness to these recommendations, they were validated by experienced cooperators with more than $94 \%$ agreement. We would like to emphasize that the recommendations have been made based on our experience in Sub-Saharan Africa low-resource setting, so they are especially directed to cooperation in these regions. Even so, many of the recommendations and suggestions that we make can be extrapolated to humanitarian medicine and surgical projects in other low- and middle-income countries due to many of them share a similar social and healthcare context.

Acknowledgements We want to thank all the members of "Cirugía Solidaria" who have participated in the development of this manuscript with their experience in this field for so many years and for their involvement in humanitarian health-care assistance and their continuous effort and affection to improve the situation in these countries.

\section{Compliance with ethical standards}

Conflict of interest The authors have nothing to disclose and declare no conflicts of interest.

\section{References}

1. Li H, Liu L, Zhang D, Xu J, Dai H, Tang N et al (2020) SARSCoV-2 and viral sepsis: observations and hypotheses. Lancet 395(10235):1517-1520

2. Laleman G, Kegels G, Marchal B, Van der Roost D, Bogaert I, Van Damme W (2007) The contribution of international health volunteers to the health workforce in sub-Saharan Africa. Human Res Health 5:19

3. Mathers CD, Fat DM, Inoue M, Rao C, Lopez AD (2005) Counting the dead and what they died from: an assessment of the global status of cause of death data. Bull World Health Organ 83(3): 171-177

4. Nthumba PM (2010) "Blitz surgery": redefining surgical needs, training, and practice in sub-Saharan Africa. World J Surg 34(3):433-437

5. Luboga S, Macfarlane SB, von Schreeb J, Kruk ME, Cherian MN, Bergström S (2009) Increasing access to surgical services in sub-saharan Africa: priorities for national and international agencies recommended by the Bellagio Essential Surgery Group. PLoS Med 6(12):e1000200
6. Murthy S, Leligdowicz A, Adhikari NK (2015) Intensive care unit capacity in low-income countries: a systematic review. PLoS ONE 10(1):e0116949

7. Rosenthal PJ, Breman JG, Djimde AA, John CC, Kamya MR, Leke RGF (2020) COVID-19: shining the light on Africa. Am J Trop Med Hyg 102(6):1145-1148

8. Wadoum REG, Clarke A (2020) How prepared is Africa to face COVID-19? Pan African Med J 35(Suppl 2):1

9. Yaya S, Otu A, Labonté R (2020) Globalisation in the time of COVID-19: repositioning Africa to meet the immediate and remote challenges. Glob. Health 16(1):51

10. Wells CR, Stearns JK, Lutumba P, Galvani AP (2020) COVID-19 on the African continent. Lancet Infect Dis 20(12):1368-1370

11. Lucero-Prisno DE 3rd, Adebisi YA, Lin X (2020) Current efforts and challenges facing responses to 2019-nCoV in Africa. Global Health Res Policy 5:21

12. Hopman J, Allegranzi B, Mehtar S (2020) Managing COVID-19 in low- and middle-income countries. JAMA 323(16):1549-1550

13. Nyazika TK, Kaela R, Mugoni M, Musomekwa K, Kyei-Baafour E, Chiwanda $S$ et al (2020) Implementation of antibody rapid diagnostic testing versus real-time reverse transcription-PCR sample pooling in the screening of COVID-19: a case of different testing strategies in Africa. mSphere 5(4):e00524-20

14. Kobia F, Gitaka J (2020) COVID-19: are Africa's diagnostic challenges blunting response effectiveness? AAS Open Res 3:4

15. Oladipo EK, Ajayi AF, Odeyemi AN, Akindiya OE, Adebayo ET, Oguntomi AS et al (2020) Laboratory diagnosis of COVID19 in Africa: availability, challenges and implications. Drug Discov Ther 14(4):153-160

16. Moletta L, Pierobon ES, Capovilla G, Costantini M, Salvador R, Merigliano $\mathrm{S}$ et al (2020) International guidelines and recommendations for surgery during Covid-19 pandemic: a systematic review. Int J Surg 79:180-188

17. Ma X, Vervoort D, Reddy CL, Park KB, Makasa E (2020) Emergency and essential surgical healthcare services during COVID-19 in low- and middle-income countries: a perspective. Int J Surg 79:43-46

18. Ademuyiwa AO, Bekele A, Berhea AB, Borgstein E, CapoChichi N, Derbew M et al (2020) COVID-19 preparedness within the surgical, obstetric, and anesthetic ecosystem in sub-saharan Africa. Ann Surg 272(1):e9-e13

19. Myles PS, Maswime S (2020) Mitigating the risks of surgery during the COVID-19 pandemic. Lancet 396(10243):2-3

20. Gil Martínez J, Rodríguez González JM, Parrilla Paricio P (2018) Cooperation in surgery of the 21st century. Cirugia Espanola 96(8):466-472

21. Gil J, Rodríguez JM, Hernández Q, Gil E, Balsalobre MD, González M et al (2012) Do hernia operations in african international cooperation programmes provide good quality? World $\mathrm{J}$ Surg 36(12):2795-3801

22. Gil J, Rodríguez JM, Gil E, Balsalobre MD, Hernández Q, Gonzalez FM et al (2014) Surgical treatment of endemic goiter in a nonhospital setting without general anesthesia in Africa. World J Surg 38(9):2212-22166

23. Gil J, Rodriguez JM, Gil E, Hernández Agúera Q, González FM, García JA et al (2015) The usefulness of international cooperation in the repair of inguinal hernias in sub-saharan Africa. World $\mathrm{J}$ Surg 39(11):2622-2629

24. Downs SH, Black N (1998) The feasibility of creating a checklist for the assessment of the methodological quality both of randomised and non-randomised studies of health care interventions. J Epidemiol Community Health 52(6):377-384

25. Akpabio A, Akintayo RO, Effiong U (2020) Can telerheumatology improve rheumatic and musculoskeletal disease service delivery in sub-Saharan Africa? Ann Rheum Dis. https://doi.org/ 10.1136/annrheumdis-2020-218449 
26. Mukwege D, Cadière GB, Vandenberg O (2020) COVID-19 Response in sub-saharan low-resource setting: healthcare soldiers need bullets. Am J Trop Med Hyg 103(2):549-550

27. Abdela SG, Berhanu AB, Ferede LM, van Griensven J (2020) Essential healthcare services in the face of COVID-19 prevention: experiences from a referral hospital in Ethiopia. Am J Trop Med Hyg 103(3):1198-1200

28. Oleribe OO, Osita-Oleribe P, Salako BL, Ishola TA, Fertleman M, Taylor-Robinson SD (2020) COVID-19 Experience: taking the right steps at the right time to prevent avoidable morbidity and mortality in nigeria and other nations of the world. Int $\mathbf{J}$ Gener Med 13:491-495

29. Kitara DL, Ikoona EN (2020) Proposed strategies for easing COVID-19 lockdown measures in Africa. Pan African Med J 36:179

30. Dahab M, van Zandvoort K, Flasche S, Warsame A, Ratnayake R, Favas $C$ et al (2020) COVID-19 control in low-income settings and displaced populations: what can realistically be done? Confl Health 14:54

31. Sahu AK, Nayer J, Aggarwal P (2020) Novel coronavirus: A capsule review for primary care and acute care physicians. J Fam Med Prim Care 9(4):1820-1824

32. Velly L, Gayat E, Quintard H, Weiss E, De Jong A, Cuvillon P et al (2020) Guidelines: Anaesthesia in the context of COVID-19 pandemic. Anaesth, Crit Care Pain Med 39(3):395-415

33. Vandenberg O, Martiny D, Rochas O, van Belkum A, Kozlakidis Z (2020) Considerations for diagnostic COVID-19 tests. Nat Rev Microbiol 14:1-13

34. Balibrea JM, Badia JM, Rubio Pérez I, Martín Antona E, Álvarez Peña E, García Botella $S$ et al (2020) Surgical management of patients with COVID-19 infection. Recommendations of the Spanish Association of Surgeons. Cirugia espanola 98(5):251-259

35. Bickler S, Ozgediz D, Gosselin R, Weiser T, Spiegel D, Hsia R et al (2010) Key concepts for estimating the burden of surgical conditions and the unmet need for surgical care. World J Surg 34(3):374-380
36. ACS (2020) COVID-19 Guidelines for Triage of Cancer Surgery Patients. ACS website. Published March 24, 2020. https://www. facs.org/covid-19/clinical-guidance/electivecase/cancer-surgery. Accessed 21 Apr. 2020

37. FFSA (2020) Clinical Guide to Surgical Prioritisation During the Coronavirus Pandemic of Federation of Surgical Speciality Associations . FFSA website. Published August 21,2020 . https:// fssa.org.uk/covid-19_documents.aspx. Accessed 25 Sep. 2020

38. Lima DL, Pereira X, Dos Santos DC, Camacho D, Malcher F (2020) Where are the hernias? A paradoxical decrease in emergency hernia surgery during COVID-19 pandemic. Hernia: J Hernias abdom Wall Surg 24(5):1141-1142

39. Köckerling F, Köckerling D, Schug-Pass C (2020) Elective hernia surgery cancellation due to the COVID-19 pandemic. Hernia: J Hernias abdom Wall Surg 24(5):1143-1145

40. Stabilini C, East B, Fortelny R, Gillion JF, Lorenz R, Montgomery A et al (2020) European Hernia Society (EHS) guidance for the management of adult patients with a hernia during the COVID-19 pandemic. Hernia: J Hernias abdom Wall 24(5):977-983

41. Shaha AR (2020) Thyroid surgery during COVID-19 pandemic: Principles and philosophies. Head Neck 42(6):1322-1324

42. Dexter F, Elhakim M, Loftus RW, Seering MS, Epstein RH (2020) Strategies for daily operating room management of ambulatory surgery centers following resolution of the acute phase of the COVID-19 pandemic. J Clin Anesth 64:109854

43. Couto RA, Wiener TC, Adams WP (2021) Evaluating postoperative outcomes of patients undergoing elective procedures in an ambulatory surgery center during the COVID-19 pandemic. Aesthet Surg J 41(2):250-257

Publisher's Note Springer Nature remains neutral with regard to jurisdictional claims in published maps and institutional affiliations. 